\title{
A VIOLÊNCIA CONTRA AS MULHERES COMO UMA VIOLAÇÃO DOS DIREITOS HUMANOS: DO POSITIVADO AO NOTICIADO
}

\author{
Brenda Fernandes \\ Centro de Estudos em Comunicação e Sociedade da Universidade do Minho (CECS/UMinho). Instituto \\ Federal de Educação, Ciência e Tecnologia do Rio Grande do Norte (IFRN). Email: \\ brendacamilli@gmail.com

\section{Carla Cerqueira} \\ Centro de Estudos em Comunicação e Sociedade da Universidade do Minho (CECS/UMinho). \\ Universidade Lusófona do Porto (ULP). Email: carlaprec3@gmail.com
}

Resumo: A violência contra as mulheres é considerada uma das mais graves e marcantes formas de violência a serem enfrentadas. Produto de construção histórica, constitui uma grave violação dos direitos humanos, tal como é postulado nas leis brasileiras e portuguesas. Este artigo apresenta um estudo exploratório sobre o Brasil e Portugal que visa compreender o modo como os meios de comunicação social tratam a violência contra as mulheres, nomeadamente quando estas são figuras públicas. Com recurso à análise de conteúdo, estudámos notícias dos dois países, sem ignorar que seus índices de violência estão em patamares distintos. Foi escolhido um caso de violência com destaque midiático em cada país nos últimos dez anos, no qual a vítima sobreviveu às agressões. Os resultados permitem concluir que a violência contra as mulheres não é tratada como uma violação dos direitos humanos pela mídia informativa, sendo apresentada majoritariamente como um caso isolado.

Palavras-chave: Violência contra as mulheres. Direitos Humanos. Normas. Mídia informativa.

Abstract: Violence against women is considered one of the most serious and striking forms of violence to be faced. As a result of a historical construction, it is a very severe violation of human rights, as it is postulated in the law of Brazil and also Portugal. This paper presents an exploratory study about these countries that aims to understand how media addresses violence against women, particularly cases involving public figures. Using the content analysis, we have studied news from Brazil and Portugal, not ignoring that 
their rates of violence stand at different levels. A case of violence highlighted by the media in the past decade, in which the victim survived, was chosen in each country. The results indicate that violence against women is not treated by the media as a violation of human rights, being mostly presented as an isolated case.

Keywords: Violence against women. Human Rights. Regulations. News Media.

\section{Introdução}

As Constituições do Brasil (1988) e de Portugal (1976) foram influenciadas por documentos internacionais, sendo um dos mais marcantes a Declaração Universal dos Direitos Humanos, adotada pela Organização das Nações Unidas em dezembro de 1948. Nesses documentos prevalece a garantia da dignidade da pessoa humana. A violência contra as mulheres é um exemplo de desrespeito da dignidade e uma das mais graves e marcantes formas de violência a serem enfrentadas pelas sociedades contemporâneas, pois ignora fronteiras, princípios e leis (Cavalcanti, 2005).
Fenômeno antigo, multifacetado e produto de uma construção histórica (Pinafi, 2007), a violência contra as mulheres precisa ser percebida como um grande problema social e cultural.

De acordo com dados da ONU Mulheres (2016), 35\% das mulheres em todo o mundo sofreram violência física ou sexual por parceiro íntimo ou nãoparceiro. ${ }^{1}$ Estudos da Organização Mundial de Saúde (OMS, 2013) mostram que, em alguns países, até $70 \%$ das mulheres sofreram violência física e/ou sexual em sua vida, provocada por um parceiro. Dias (2008: 16) exalta a gravidade desta violência e ressalta que, por mais que os dados sejam surpreendentes, é preciso perceber que a violência é subnotificada: "somente $10 \%$ das agressões sofridas por mulheres são levadas ao conhecimento da polícia" (2008: 17). Simões (2011: 266) corrobora a ideia de que a violência contra as mulheres é uma questão de desrespeito pelos direitos humanos e é dever do Estado evitar e responsabilizar-se por esses abusos, sejam cometidos na esfera privada ou

\footnotetext{
${ }^{1}$ Facts and Figures: Ending Violence Against Women.
} 
na esfera pública, pois se tratam de crimes contra a humanidade.

A Agência dos Direitos Fundamentais da União Europeia (FRA) publicou, em 2014, o relatório "Violência contra as mulheres: um inquérito à escala da União Europeia", onde refere que uma a cada três mulheres, desde os 15 anos, foi vítima de violência, pelo menos, uma vez na vida. Os resultados do inquérito mostram que a violência contra as mulheres é uma violação dos direitos humanos frequente, mas raramente denunciada (FRA, 2014: 9). Como Estado-Membro da União Europeia, Portugal faz parte deste cenário, sendo que o relatório menciona que $19 \%$ das mulheres portuguesas, a partir dos 15 anos de idade, foram vítimas de violência física e/ou sexual por parte de parceiro atual ou anterior (FRA, 2014: 20). Portugal está situado entre os dez países europeus com menos vítimas de violência contra as mulheres. Apesar desta informação, baseada nos registros oficiais, o número de vítimas em Portugal ainda é assustadoramente relevante, já que pelo menos um quarto das portuguesas já vivenciou um caso de agressão (FRA, 2014). Em 2015, do total de mulheres assassinadas, $87 \%$ delas mantinham ou haviam mantido uma relação de intimidade com os homicidas, segundo o Observatório das Mulheres Assassinadas da organização UMAR. $^{2}$

No Brasil, a cada cinco minutos, uma mulher é agredida, vítima de violência doméstica (SPM, 2012). A cada ano, cerca de quatro mil mulheres são assassinadas. Um estudo de 2014 do Instituto de Pesquisa Econômica Aplicada (IPEA) apresenta resultados preocupantes. Foram ouvidas 3.810 pessoas em todo o país e mais da metade das pessoas entrevistadas $(58.5 \%)$ concorda com a ideia de que "se as mulheres soubessem como se comportar, haveria menos estupros". Quase metade (47.2\%) concorda totalmente com a frase de que "o que acontece com o casal em casa não interessa aos outros" e mais da metade $(58.4 \%)$ anui totalmente com a frase "Em briga de marido e mulher, não se mete a colher". Por um lado, demonstra uma cultura de culpabilização da vítima pela violência sexual sofrida, por ela supostamente não saber se comportar adequadamente. Por outro, revela que

\footnotetext{
${ }^{2}$ União de Mulheres Alternativa e Resposta.
} 
grande fatia das/os entrevistadas/os acredita que o que acontece com um casal é do domínio privado, ainda que ocorram agressões no ambiente familiar. Dias (2008: 20) salienta que a "idéia da família como uma entidade inviolável, não sujeita à interferência nem da Justiça, faz com que a violência se torne invisível, protegida pelo segredo".

Estas interpretações possuem não só fundamentos históricos, assentes nas bases de uma sociedade de matriz androcêntrica, mas também legislativos. Até poucas décadas, o crime de violência contra as mulheres não possuía regulamentação específica, só podendo ser iniciada uma demanda judicial após a queixa apresentada pela vítima e, caso ela se arrependesse e quisesse retirar a queixa, o Ministério Público nada poderia fazer. Hoje, tanto no Brasil quanto em Portugal, é possível iniciar um processo judicial para apurar uma agressão contra uma mulher ${ }^{3}$, mesmo que ela não apresente queixa, por tratar-se de um crime público como se diz em Portugal ou, no Brasil, um crime cuja ação penal é pública

3 Em Portugal, a lei refere-se à violência doméstica em geral, podendo a vítima ser qualquer pessoa envolta no núcleo familiar. incondicionada, não dependendo mais da representação da vítima, nos termos da decisão do Supremo Tribunal Federal (STF) ao julgar a Ação Direta de Inconstitucionalidade (ADI) 4424. ${ }^{4}$

Os avanços legislativos para evitar e punir a violência contra as mulheres são perceptíveis nos dois países supramencionados, especialmente nas últimas décadas. Porém, a sociedade nem sempre acompanha as mudanças legislativas. Como mostram os dados do estudo do IPEA (2014), uma parcela das/os entrevistadas/os apresenta-se hesitante (ou despreocupada) quanto a crimes contra as mulheres por acreditar que este tipo de crime diz respeito à esfera privada. Machado (2004) entende que a configuração jurídica da esfera privada se fundamenta também em classificações do que é ou não considerado 'normal'. De forma análoga, poder-se-ia dizer que as/os entrevistadas/os percebem a violência contra as mulheres como uma 'situação normal'.

\footnotetext{
${ }^{4} \mathrm{O}$ artigo 16 da lei $11.340 / 2006$ dispõe que as ações penais públicas "são condicionadas à representação da ofendida", mas, para a maioria dos ministros do STF, essa circunstância acaba por esvaziar a proteção constitucional assegurada às mulheres.
} 
Enquanto exímio conhecedor da linguagem, o campo jornalístico pode influenciar os seus públicos através dos conteúdos noticiados, razão pela qual importa perceber como a violência contra as mulheres é (re)apresentada. Silveirinha (2004: 6) destaca que "a linguagem envolve $o$ processo semiótico (símbolos, signos e códigos), a cultura envolve o processo de conceitos, imagens e ideias partilhada, e o significado deriva de experiências individuais e colectivas, de saber e compreender". Neste sentido, a autora refere que os discursos midiáticos, tal como os discursos de outros agentes de socialização, têm sustentado os interesses do patriarcado e do capitalismo (2004: 7).

No presente artigo, pretendemos auscultar como a mídia, enquanto agente de socialização marcante, faz a cobertura dos casos de violência contra as mulheres, de modo a perceber se este tipo de violência é tratado como uma violação dos direitos humanos. Apesar de consolidadas investigações que cruzam as temáticas da mídia, gênero e crime (e.g., Gallagher, 1995; Penedo, 2003; Carter, 2004; Silveirinha, 2004; Zoonen, 2004), este estudo pretende dar um contributo inovador no sentido de perceber até que ponto as notícias cotidianas sobre os crimes contra as mulheres - figuras públicas demonstram a sua gravidade e tratam esta forma de violência como uma violação dos direitos humanos.

Optámos por analisar notícias do Brasil e de Portugal, com o objetivo de dar ao estudo um caráter transnacional e comparativo de países que, embora tenham o mesmo idioma, são de diferentes continentes, tamanhos e possuem índices de violência doméstica em patamares distintos. Foi escolhido um caso midiático de violência contra as mulheres de destaque em cada país, nos últimos dez anos, nos quais a vítima sobreviveu às agressões e cujas partes envolvidas são pessoas públicas. Entendemos ser relevante analisar casos em que a vítima e o agressor são pessoas públicas pois, como sustenta Silveirinha (apud Simões, 2011: 386), existem "certamente razões para considerar que as notícias de «violência doméstica» cometida por «celebridades» podem contribuir para a consciencialização geral do fenómeno". Por isso, consideramos que é importante perceber se a mídia informativa 
aproveitou o caso famoso para conscientizar as/os leitoras/es sobre a gravidade do crime sob análise/julgamento, a necessidade de denunciá-lo e o caráter público deste tipo de crime/violação dos direitos humanos.

Este estudo se justifica, ainda, pois conforme Stanko sustenta (1990 apud Carter, 2004: 15), há uma negação social na medida em que esta forma de violência acontece em privado. Mesmo quando é publicamente reconhecida (através da mídia), a violência na esfera doméstica é vista de maneira < banal»», embora não aceitável. "Ela sugere que muitas pessoas vêem a violência privada como uma parte quase <inevitável» das relações heterossexuais «nnormais»»" (Carter, 2004: 15). Como a mídia do Brasil e de Portugal vêem a violência contra as mulheres? Será que a tratam como uma violação dos direitos humanos ou como um episódio banal? Estas são perguntas que pretendemos responder neste estudo exploratório.

\section{Do positivado: a violência e as normas no Direito}

A vida em sociedade está conectada ao Direito. No atual estágio dos conhecimentos jurídicos, é predominante o entendimento de que não há sociedade sem direito: $u b i$ societas ibi jus (Cintra et al., 2009). A positivação de ideias, ou seja, a normatização de condutas e direitos é um importante meio para evitar o desrespeito à dignidade humana e desencadear mudanças sociais. No entanto, há pontos em que o Direito, especialmente dos séculos passados, contribui(u) para a manutenção da sociedade patriarcal e a normalização de práticas preconceituosas. ${ }^{5}$ Duarte (2013: 16), que analisou a evolução legislativa do crime de violência doméstica em Portugal, apresentou em suas reflexões finais que "é consensual entre as diferentes feministas que o Direito tem historicamente contribuído para a perpetuação, legitimação e/ou reprodução de relações patriarcais". Numa ótica diferente, Simões (2011: 265) menciona que, apesar do movimento feminista apresentar abordagens e enfoques muito díspares ao longo dos tempos, um denominador comum tem sido o entendimento do

5 O CC/1916 referia a indissolubilidade do casamento e a capacidade relativa da mulher. $\mathrm{O}$ artigo 233[...] designava o marido como único chefe da sociedade conjugal. 
Direito como mola propulsora do progresso.

A violência contra as mulheres é uma forma de desrespeito à dignidade e à igualdade dos seres humanos. É uma prática que transmite a ideia de que as mulheres são inferiores aos homens. As normas que cuidam da violência contra as mulheres ou dos direitos humanos em geral têm em comum a busca pela dignidade. Esta forma de violência demorou a ser oficialmente considerada e declarada uma violação dos direitos humanos. O primeiro documento de destaque a reconhecê-la foi a Declaração das Nações Unidas sobre a Eliminação da Violência Contra as Mulheres, produto da Conferência Mundial sobre Direitos Humanos, realizada em Viena, em 1993 (Weldon e Htun, 2013: 241). A declaração da violência contra as mulheres como uma violação dos direitos humanos impôs aos Estados a responsabilidade por eventuais abusos, sejam eles cometidos na esfera pública ou privada, tornandose marco no reconhecimento da violência como sendo do domínio público.

Conforme escrito no preâmbulo da Declaração, a violência é "uma manifestação de relações de poder historicamente desiguais entre homens $\mathrm{e}$ mulheres que conduziram à dominação e à discriminação contra as mulheres pelos homens e que impedem o pleno progresso das mulheres". Por esta razão, não pode ser considerada uma violência qualquer ou um ato isolado, pois reflete valores arraigados na sociedade, o que pode conduzir, por vezes, ao entendimento de que a vítima, mulher, é a culpada da agressão sofrida, ${ }^{6}$ como se a agressão pudesse ser justificada.

Ainda em dimensão internacional, é indispensável mencionar a Quarta Conferência Mundial sobre as Mulheres ocorrida em Pequim, em 1995, pois esta significou um importante marco para discutir as políticas, programas e legislações com o recorte de gênero (Miranda, 2012). Na Declaração e Plataforma de Ação de Pequim, que resultou da referida conferência, foram identificadas doze áreas temáticas de preocupação prioritária, dentre as quais a violência contra as mulheres, as lacunas na

6 Segundo o IPEA, em 2014, 26\% das/os entrevistadas/os concorda com a afirmação de que "mulheres que mostram o corpo merecem ser atacadas". Em 2016, o Brasil tem assistido inúmeros casos de estupros coletivos e, na maioria deles, a sociedade tem julgado, inicialmente, a vítima. 
promoção e proteção dos direitos das mulheres e o tratamento estereotipado dos temas relativos às mulheres nos meios de comunicação social e a desigualdade de acesso a esses meios. Sobre cada uma das áreas temáticas foram pensados objetivos a serem alcançados, bem como estratégias de ação. Em 2015, vinte anos após a Quarta Conferência Mundial sobre as Mulheres, ativistas e líderes mundiais se reuniram na sede das Nações Unidas em Nova Iorque e fizeram um balanço dos avanços e desafios pendentes desde a Plataforma de Pequim. Dentre os avanços, pode-se destacar que mais mulheres têm participado da vida política, que a maioria dos países garante a proteção legal contra a violência e suas Constituições determinam a igualdade de gênero. Por outro lado, em média, as mulheres continuam ganhando menos do que os homens, faltam leis que garantam seus direitos reprodutivos e um terço delas sofre violência física ou sexual ao longo da vida.

Em âmbito regional, as Américas e a Europa têm regras específicas sobre o assunto: respectivamente, a Convenção
Interamericana para Prevenir, Punir e Erradicar a Violência contra as Mulheres (Convenção de Belém do Pará de 1994) e a Convenção sobre a Prevenção e Combate à Violência contra as Mulheres e Violência Doméstica (Convenção de Istambul de 201477). A Convenção de 1994 serviu como parâmetro para a formulação de leis nacionais nos países dela signatários, como o Brasil. Foi a principal referência utilizada para a formulação da Lei "Maria da Penha". A Convenção de Istambul, do Conselho da Europa, insta os Estados-membros a melhorar a proteção das vítimas de violência e garantir a instauração de ação penal contra os agressores. Tanto a Convenção de Belém do Pará quanto a Convenção de Istambul reconhecem a violência contra as mulheres como uma violação dos direitos humanos.

No âmbito interno dos países, pode ser mencionada a lei brasileira $n$. 11.340/2006, conhecida como "Lei Maria da Penha", reconhecida pelas Nações Unidas como uma das três melhores leis do mundo no combate à violência contra as mulheres, a qual prevê em seu artigo $6^{\circ}$ que a violência

\footnotetext{
${ }^{7}$ Aberta a assinaturas em 2011 e ratificada em 2014, ao conseguir a adesão de 10 Estados.
} 
doméstica e familiar contra as mulheres constitui uma forma de violação dos direitos humanos. Além da mencionada Lei n. 11.340/2006, outra norma relevante é o Código Penal alterado pela Lei n. $13.104^{8}$ de março de 2015 , que introduziu o chamado feminicídio. Foi acrescentado como uma circunstância qualificadora do crime do artigo $121, \S$ $2^{\circ}$ do Código, que trata do homicídio qualificado. Esta qualificadora ocorrerá quando o crime for praticado contra uma mulher por razões da condição de sexo feminino. ${ }^{9}$

Portugal possui leis que cuidam da violência doméstica de forma genérica, abrangendo a violência em relação aos filhos, ao próprio marido/companheiro/namorado ou entre casais do mesmo sexo, de acordo com o artigo $152^{\circ}$ do Código Penal português de 1995, alterado pela Lei n. 59/2007,

\footnotetext{
${ }^{8}$ Alterou a Lei n. 8.072/90, que dispõe sobre os crimes hediondos, para incluir o feminicídio. A condenação em crime hediondo determina o cumprimento de um maior período de pena no regime fechado antes de se progredir para outro regime de pena. A classificação como crime hediondo impede que os acusados sejam libertados após o pagamento da fiança.

9 O $\S 2^{\circ}$-A explica que se considera que há razões de condição de sexo feminino quando o crime envolve violência doméstica e familiar ou menosprezo ou discriminação à condição de mulher. Tal circunstância é chamada de feminicídio. O femicídio refere-se, por outro lado, à morte de uma mulher.
}

que introduziu o crime de violência doméstica. $\mathrm{O}$ artigo $152^{\circ}$ prevê pena de prisão de um a cinco anos para quem praticar maus tratos a pessoa menor ou indefesa em virtude de idade, deficiência, doença ou gravidez, bem como a quem praticar maus tratos ao cônjuge ou pessoa que viva com o agressor em condições análogas às dos cônjuges. A Lei n. 112/2009 determina proteção específica para as vítimas do crime. Trata-se de um crime público, conforme disciplina a Lei n. 7/2000. Em 2013, Portugal ratificou a Convenção de Istambul, sendo o primeiro país da União Europeia a fazê-lo.

Apesar dos esforços legislativos internacionais, regionais e nacionais, da criação de leis, medidas e recomendações, os índices de violência contra as mulheres continuam elevados, o que faz perceber que, apesar da relevância do direito positivado nas normas e dos avanços legislativos, é preciso ir além, descobrindo novas causas, medidas de prevenção e buscando soluções para combater este fenômeno complexo e multifacetado.

\section{Do noticiado: a mídia informativa e a violência contra as mulheres}


O papel da mídia não é exclusivamente o de informar. Burgelin (apud Ponte, 2004: 12) enfatiza que as/os leitoras/es procuram nos jornais mais do que informação; procuram um sentido de ordem e de controle que se sobreponha à desordem do mundo, poupando-lhes "o pânico insuperável que não poderia deixar de lhes provocar um universo de guerras e de catástrofes que estivessem privados de significação" (Burgelin, 1970 apud Ponte, 2004: 12).

Os meios de comunicação social influenciam a vida da sociedade, pois são uma das mais importantes fontes de (in)formação. A forma como os conteúdos noticiosos são transmitidos e os acontecimentos narrados é vista como um veículo de significações, uma teia de significados, nem sempre explícitos ou diferenciados (Penedo, 2003).

Muito para além da nossa vivência directa de cidadania, é através dos media que o mundo nos chega - factos, acontecimentos, histórias, relatos, testemunhos e imagens - e é, também, por esta via que formamos opiniões, reforçamos crenças, [...] (2003: 13).
Em razão da importância/poder dos meios de comunicação social, percebe-se que podem ter uma ação positiva e decisiva em temáticas relevantes da sociedade, como a dos direitos das mulheres. Rajs (2014: 43) relembra que esta importância/poder pode ser utilizada de forma fomentadora ou enfraquecedora dos direitos das mulheres. Simões (2014: 34-35) explica que a perspectiva feminista tem sido crítica "em relação às intencionalidades subjacentes à ação das forças que estão no epicentro da construção simbólica de diversos fenómenos, particularmente os media". Apesar de os estudos feministas dos media reconhecerem o incremento da visibilidade da violência contra as mulheres como algo emancipador, advertem para a contingência dessa visibilidade. Simões enfatiza ainda que:

Com frequência, formas de violência que configuram, no direito internacional, um problema da ordem dos direitos humanos são retratadas como questões privadas e pessoais das mulheres. [...] no momento em que as agressões contra as mulheres perpetradas por um parceiro íntimo contornam a 
barreira que as separa da publicidade, estas não tendem a ser objeto de um profundo e aturado debate (2014: 35).

Nos últimos anos, a maioria dos casos de violência contra as mulheres que repercutiu na mídia brasileira, envolvendo pessoas públicas, teve uma mulher como vítima fatal. $^{10}$ Em Portugal, por outro lado, na maioria dos casos de violência contra as mulheres debatidos pela mídia, a vítima sobreviveu. ${ }^{11}$ Apesar de esse tipo de violência não ser um fenômeno novo, a extensão de sua percepção como um problema de domínio público varia com o tempo. A cobertura midiática é um dos principais fatores que influenciam tal variação (Maxwell et al., 2000).

\footnotetext{
10 Em 1992, Daniela Perez foi assassinada por um ator com quem contracenava; a jornalista Sandra Gomide, em 2000, por seu namorado; em 2010, foi a advogada Mércia Nakashima e o principal suspeito é seu ex-namorado. No mesmo ano, o goleiro de um grande clube do Brasil foi preso por envolvimento no assassinato de uma mulher com quem se relacionou.

11 Caso entre o ex-jornalista Artur Albarran e sua mulher, em 2003, que queixou-se de violência doméstica; porém, ele disse que ela sofria de doença mental. O MP não conseguiu provas suficientes e Albarran foi considerado inocente em 2005. O cantor Paco Bandeira foi condenado, em 2012, a três anos de prisão por violência doméstica contra sua ex-companheira Maria Roseta Ferreira. O médico espanhol José Maria Tallon foi acusado de violência por sua ex-mulher, Catarina Fortunato de Almeida. O processo judicial foi suspenso. Ela lançou um livro contando o drama vivido.
}

Através do slogan "o pessoal é político", associado aos movimentos feministas da década de 1960/70, sugere-se que nem pessoas, nem ações, nem atributos pessoais devem ser excluídos da discussão pública e da tomada de decisões, embora a autodeterminação da privacidade possa ainda assim manter-se (Young, 1998 apud Silveirinha, 2006: 70). É imprescindível deslegitimar o discurso de dominação que contribui para a opressão das mulheres no espaço doméstico, especificamente no que concerne às relações assimétricas que se materializam em atos de violência. Representar as situações de violência enquanto casos particulares reforça a ideia de patologia ou desvio e não de um problema social. Além disso, Carter (2004: 15) afirma que este tipo de notícias se tornaram banais, pelo que se faz necessário que os discursos de notícias parem de reproduzir formas hierárquicas de diferença de gênero.

Em suma, enquanto a temática era apresentada inicialmente como sendo da esfera privada (Zoonen, 2004), pode falar-se atualmente de uma coexistência de abordagens, as quais são muitas vezes contraditórias: por um 
lado, descortina-se o problema e leva-se à denúncia e, por outro, trivializa-se (Ross, 2007).

\section{Metodologia}

Para analisar o modo como a mídia informativa trata a violência contra as mulheres, utilizámos inicialmente expressões-chave ${ }^{12}$ e um motor de busca (o google) para perceber qual foi o caso que - envolvendo pessoas públicas, no Brasil e em Portugal, no qual a vítima sobreviveu às agressões - foi o mais mencionado nos últimos dez anos pela imprensa de seu respectivo país. $\mathrm{O}$ caso de maior repercussão no Brasil, seguindo os parâmetros mencionados, ocorreu em 2008 entre os atores Luana Piovani e Dado Dolabella. Em Portugal, o caso de maior repercussão veio a público em 2013 entre a apresentadora de televisão Bárbara Guimarães e o ex-Ministro da Cultura Manuel Maria Carrilho.

Ressalte-se que no contexto da sociedade da informação, a pesquisa realizada em sites de busca através da internet, usando expressões-chave, constitui uma técnica de coleta de dados

12 E.g. "violência contra as mulheres no Brasil/Portugal" e "famosos casos de violência doméstica". pertinente (Fidalgo e Mill, 2007), uma vez que é um dos meios de informação cada vez mais utilizados. No sentido de não enviesarmos a pesquisa, optámos por um motor de busca enquanto meio principal, o qual nos permitiu perceber os casos mais acessados nas mídias informativas dos países.

A opção por casos cujas vítimas sejam pessoas públicas e que estejam vivas se deu em razão de que estas poderiam funcionar como modelo de referência para outras mulheres vítimas deste tipo de violência (pois são midiáticas por si mesmas), bem como poderiam ser ouvidas pela imprensa, demonstrar a continuação da vida após a violência, presenciar e participar do desenrolar do caso na mídia e no Judiciário.

Determinados os casos a serem estudados, realizou-se nova pesquisa ${ }^{13}$ para coletar notícias relacionadas aos mesmos. A fase de coleta de dados decorreu entre 15 de março e 8 de maio de 2015, quando mais de 40 textos diferentes foram encontrados. Deste conjunto, foram selecionados aleatoriamente para análise os sete

\footnotetext{
${ }^{13}$ Novamente, utilizando expressões-chave como os sobrenomes das partes e a palavra "violência".
} 
primeiros textos jornalísticos que continham um título, que não eram anônimos e possuíam mais de 20 linhas sobre o caso. Os textos analisados são provenientes de mídia informativa digital dos dois países. Evidencia-se a abordagem metodológica de estudo de caso e a análise de conteúdo como técnica para análise dos dados.

Para a análise de cada peça jornalística, foram utilizadas duas categorias semânticas de análise (Gil, 2014), a saber: o "tratamento noticioso da violência" e o "olhar sobre as partes envolvidas". Para a primeira categoria "tratamento noticioso da violência" -, estabelecemos as seguintes subcategorias: a "violência como violação dos direitos humanos $\mathrm{e}$ desrespeito à dignidade", as "normas penalizadoras" e a "dicotomia entre a esfera pública e privada”. Para a segunda categoria - "olhar sobre as partes envolvidas" -, utilizámos três subcategorias: o "foco no crime ou no rompimento do relacionamento", a "vida pregressa dos envolvidos" e a "tendência de responsabilização da vítima". Estas escolhas metodológicas se justificam, pois nosso objetivo é auscultar como a mídia informativa faz a cobertura dos casos de violência contra as mulheres, se trata este tipo de violência como uma violação dos direitos humanos ou promove a culpabilização da vítima, se deixa de abordar o tema com profundidade para focar no relacionamento e o remete para a esfera privada, se menciona legislação neste domínio.

É importante frisar que este estudo exploratório não tem a pretensão de gerar dados representativos da cobertura noticiosa de todos os casos que envolvem figuras públicas, em face das inúmeras peculiaridades que cada caso e a cobertura midiática carregam consigo. Pretende-se, ao invés, a familiarização com 0 fenômeno estudado, proporcionando uma visão de dois casos concretos de violência contra as mulheres sob o prisma do tratamento desta como uma violação dos direitos humanos, de modo a viabilizar estudos futuros mais aprofundados.

\section{Análise e discussão}

\section{Brasil: caso Piovani x Dolabella}

$\mathrm{O}$ caso de violência contra as mulheres ocorrido no Brasil envolveu dois atores, Luana Piovani e Dado Dolabella, que namoravam há mais de 
dois anos. A agressão ocorreu em uma boate quando Dolabella teria tentado puxar Piovani, que foi defendida por amigos e, na confusão, atingiu a camareira de Piovani, de 62 anos, que ficou impossibilitada de trabalhar por 20 dias, com os braços imobilizados.

Apesar de ser um caso de violência isolado, fugindo do padrão dos casos de violência entre companheiros/as, gerou um número incalculável de notícias por envolver pessoas famosas e por gerar discussões jurídicas (e jurisprudenciais, até de tribunais superiores) sobre a aplicação da Lei Maria da Penha. Foram analisados sete textos jornalísticos, conforme a Tabela 1:

Tabela 1: Textos informativos analisados (Brasil)

\begin{tabular}{|c|c|c|c|}
\hline Títulos & $\begin{array}{c}\text { Mídia } \\
\text { Informativa }\end{array}$ & Data & Autoria por \\
\hline 1) Jamais vai ter volta & Portal Terra & Novembro/2008 & $\begin{array}{l}\text { Duas } \\
\text { mulheres }\end{array}$ \\
\hline $\begin{array}{l}\text { 2) Violência doméstica não } \\
\text { acontece apenas no anonimato }\end{array}$ & $\begin{array}{l}\text { Jornal } \\
\text { Contraponto } \\
\text { Online }\end{array}$ & Setembro/2010 & Uma mulher \\
\hline $\begin{array}{l}\text { 3) Condenado novamente, Dado } \\
\text { Dolabella tenta evitar cadeia }\end{array}$ & Portal IG & Setembro/2011 & Uma mulher \\
\hline $\begin{array}{l}\text { 4) Agressão de Dado Dolabella a } \\
\text { Luana Piovani é considerada lesão } \\
\text { corporal simples pela Justiça }\end{array}$ & Portal UOL & Outubro/2012 & Um homem \\
\hline $\begin{array}{c}\text { 5) Justiça anula condenação de } \\
\text { Dado Dolabella por agressão a } \\
\text { Luana Piovani }\end{array}$ & Revista Veja & Julho/2013 & Uma mulher \\
\hline $\begin{array}{l}\text { 6) A lei que não protege as } \\
\text { mulheres }\end{array}$ & Jornal Opção & Julho/2013 & Um homem \\
\hline $\begin{array}{l}\text { 7) Luana Piovani comemora } \\
\text { sentença de Dado Dolabella }\end{array}$ & Diário24h & Abril/2014 & Um homem \\
\hline
\end{tabular}


A peça "A lei que não protege as mulheres", assim como as demais, detalha o caso de Piovani e Dolabella, bem como as decisões judiciais que o envolvem. Destaca-se por criticar a Lei Maria da Penha e elogiar a decisão do desembargador que disse que esta não deveria ser aplicada ao caso, mencionando outros exemplos de violência para respaldar a ineficiência do Estado/lei. Apresenta dispositivos legais, inclusive da Lei n. 11.340; porém, nada explana sobre violação dos direitos humanos ( $6^{\circ}$ artigo da lei). Foca em crimes, na aplicação e (in)eficácia da Lei Maria da Penha. Não apresenta tendência de responsabilizar a vítima, apesar de não tratá-la exatamente como uma vítima ao referir que "como exigir que ela seja usada na proteção de uma atriz global, que pode dispor de segurança particular e conta com farto espaço na imprensa para denunciar seu algoz?".

Em sentido oposto, enfatizando a importância da Lei n. 11.340, bem como sua aplicabilidade ao caso sob análise, está a peça “Luana Piovani comemora sentença de Dado Dolabella". Inicia citando que Piovani comemorou a decisão do STJ, que revogou a decisão do Tribunal de Justiça do Rio de Janeiro que entendia que a Lei Maria da Penha só deveria ser aplicada em casos em que as vítimas fossem mulheres "oprimidas ou subjugadas aos caprichos de um homem". A peça destaca ainda que a atriz entendeu ter ocorrido justiça, tendo afirmado que a questão é primordial "para a dignidade da mulher brasileira".

Nenhum dos textos midiáticos apresentados discute a dicotomia entre esfera pública e privada, não se refere que é um crime público e/ou uma situação particular dos envolvidos, alheia e desimportante à sociedade. Do mesmo modo, nenhum apresenta a violência contra as mulheres como uma violação dos direitos humanos, nem a enforma diretamente como um desrespeito à dignidade. Esta ausência de discussão sobre a violência contra as mulheres como uma violação dos direitos humanos ou mesmo como um problema social demonstra que a imprensa tem, em grande parte, vislumbrado os crimes como casos isolados, com razões e caminhos próprios. Percebe-se a banalização da violência, como já foi enunciado por Carter (2004: 15). Apenas a peça n. 2 
tenta problematizar (ainda que superficialmente) e sensibilizar a população para o fenômeno da violência contra as mulheres, explicitando nomes de outras pessoas públicas vítimas deste tipo de violência e, ainda, disponibilizando o número do disquedenúncia e da delegacia da mulher.

Dos sete textos apresentados, uma peça (n. 1) tem seu enfoque voltado para o rompimento da relação do casal e seis têm seus enfoques voltados ao crime (ainda que indiretamente) e à aplicação da Lei Maria da Penha e/ou decisões judiciais, o que pode contribuir para conscientizar a população sobre a complexidade da situação. Porém, dentre estes, um texto (n. 6) tenta conscientizar as/os leitoras/es contra a aplicação da Lei Maria da Penha, por compreendê-la injusta para as próprias mulheres (supostamente tratando-as como seres inferiores). Apenas uma peça (n. 1) menciona algo sobre a vida pregressa do agressor, o que ocorre indiretamente, através da fala de seu irmão, sobre serem "meninos bem criados, de família", que não batem em mulher. A peça n. 3 traz, porém, uma nova acusação de violência doméstica contra
Dolabella, feita por sua ex-mulher (relacionamento posterior ao estudado). Nenhum texto apresenta a tendência de responsabilizar a vítima pela agressão sofrida; todavia, duas peças (n. 5 e 6 ) demonstram que a Lei Maria da Penha não deveria ser aplicada ao caso, por entender que a vítima não precisaria de qualquer benefício legal, em face de sua "autossuficiência" e independência financeira, o que demonstra profundo desconhecimento do fenômeno de violência contra as mulheres e das razões teleológicas da lei.

\section{Portugal: caso Guimarães $x$ Carrilho}

O caso de violência ocorrido em Portugal envolveu uma apresentadora de televisão e um filósofo, ex-ministro da cultura de Portugal. O caso tornou-se público em outubro de 2013 quando Carrilho dirigiu-se a casa, após chegar de uma viagem, mas foi impedido de entrar. Guimarães ajuizou pedido de divórcio e queixou-se de violência física e psicológica continuada. Carrilho também iniciou demanda judicial contra Guimarães por violência doméstica, alegando que a distância dos filhos e a impossibilidade de entrar em sua casa lhe geraram danos psíquicos. Foram 
analisados sete textos jornalísticos, conforme a Tabela 2:

Tabela 2: Textos informativos analisados (Portugal)

\begin{tabular}{|c|c|c|l|}
\hline Títulos & $\begin{array}{c}\text { Mídia } \\
\text { Informativa }\end{array}$ & Data & Autoria por \\
\hline $\begin{array}{c}\text { 1) Tribunal proíbe Carrilho de } \\
\text { contactar Bárbara Guimarães por } \\
\text { suspeita de violência doméstica }\end{array}$ & Público & Fevereiro/2014 & Uma mulher \\
\hline $\begin{array}{c}\text { 2) Carrilho nega ter agredido } \\
\text { Bárbara na escola dos filhos }\end{array}$ & $\begin{array}{c}\text { Diário de } \\
\text { Notícias }\end{array}$ & Junho/2014 & Uma mulher \\
\hline $\begin{array}{c}\text { 3) Carrilho acusa Governo de acto } \\
\text { "ilegal e inconstitucional" ao } \\
\text { convidar ex-mulher para jornadas } \\
\text { de violência doméstica }\end{array}$ & Público & Novembro/2014 & Uma mulher \\
\hline $\begin{array}{c}\text { 4) Bárbara Guimarães vai ser } \\
\text { julgada por violência doméstica } \\
\text { contra Carrilho }\end{array}$ & Público & Janeiro/2015 & Uma mulher \\
\hline $\begin{array}{c}\text { 5) Acusado de ameaçar vida da ex- } \\
\text { mulher e filhos, Carrilho nega tudo }\end{array}$ & Público & Janeiro/2015 & Uma mulher \\
\hline $\begin{array}{c}\text { 6) Carrilho ameaçou publicar fotos } \\
\text { de Bárbara nua na Net }\end{array}$ & $\begin{array}{l}\text { Jornal de } \\
\text { Notícias } \\
\text { de facebook de Bárbara }\end{array}$ & Janeiro/2015 & Uma mulher \\
\hline $\begin{array}{c}\text { 7) Carrilho defende-se na dégina } \\
\text { Notícias }\end{array}$ & Janeiro/2015 & Uma mulher \\
\hline
\end{tabular}

Na peça n. 4, a jornalista inicia dizendo que Guimarães será julgada pelo crime de violência doméstica devido a "uma conduta de maus-tratos psicológicos" contra Carrilho, segundo o despacho de pronúncia do crime. $\mathrm{Na}$ sequência, a peça jornalística menciona, sem detalhamentos, que Carrilho também é acusado de violência doméstica. Não se fala sobre penas e punições, mas menciona a legislação. Refere o desrespeito à dignidade ao copiar os termos do despacho de 
pronúncia, mas o enfoque dado é no desrespeito à dignidade de Carrilho.

O texto n. 5 dá detalhes sobre o despacho do Ministério Público contra Carrilho e, buscando a imparcialidade jornalística, concede espaço para a resposta de Carrilho. Finaliza contando que Guimarães mudou a fechadura de casa, contratou dois seguranças e iniciou os papéis do divórcio, depois de uma viagem do então marido. Nada foi mencionado sobre a pena pelo crime de violência doméstica ou sobre desrespeito à dignidade. Foca o crime. Não exibe a tendência de responsabilizar a vítima.

Nenhuma das peças jornalísticas analisadas apresenta a dicotomia entre a esfera pública e privada, nem a violência contra as mulheres é tratada como uma violação dos direitos humanos. Apenas a peça n. 4 menciona, sem aprofundamento, o crime de violência doméstica como um desrespeito à dignidade. Nada falam diretamente sobre a vida pregressa dos envolvidos. Não apresentam tendência de responsabilizar a vítima pela agressão sofrida diretamente, apesar de que ao citar pronunciamentos de Carrilho esta ideia está implícita em algumas notícias ${ }^{14}$. Duas notícias falam sobre normas penalizadoras (uma sobre o Código de Processo Penal - n. 4 - e outra sobre o Código Penal/violência doméstica - n. 1), mas apenas uma destas (n. 1) menciona penas e punições e explica os detalhes do crime de violência doméstica.

Dentre os textos apresentados, cinco focam no crime que está sendo investigado, bem como em normas penalizadoras e/ou em aspectos judiciais, especialmente relacionados ao Tribunal de Instrução Criminal de Lisboa e/ou a despacho do Ministério Público. Uma peça (n. 2), apesar de mencionar o possível crime e a separação do casal, não apresenta enfoque específico em nenhum dos dois assuntos. Outra (n. 3) se atém a tratar de acusações de Carrilho ao Governo por supostamente o Poder Executivo ter convidado Guimarães a participar de jornadas sobre violência doméstica para prejudicá-lo.

A cobertura jornalística dos casos de violência contra as mulheres no Brasil e em Portugal apresenta

\footnotetext{
${ }^{14}$ Percebe-se, por exemplo, em: Tribunal proíbe Carrilho de contactar Bárbara Guimarães por suspeita de violência doméstica.
} 
semelhanças e divergências. $O$ caso português difere do brasileiro por, entre outras coisas, apresentar uma continuação delituosa, bem como a suposta prática de mais de um tipo de crime. Carrilho, a nosso ver, comete violência psicológica/moral em vários relatos apresentados pelos textos jornalísticos estudados ${ }^{15}$. Guimarães parece estar sendo vítima de violência mesmo após o rompimento, publicamente, em várias declarações. $\mathrm{O}$ tom das declarações do agressor, reproduzidas pela mídia, é extremamente ofensivo. Causa estranheza que nenhum/a jornalista tenha mencionado isso após as transcrições. No caso brasileiro, não se percebe violência nas falas do agressor, nem da vítima. Os aspectos judiciais foram tratados com mais detalhamento no caso português, apesar de os dois terem apresentado geralmente diálogos entre crime, normas penalizadoras e decisões judiciais, o que indica um aprofundamento dos textos jornalísticos, ou seja, não se limitaram a narrar $\mathrm{o}$ ocorrido. $\mathrm{O}$ tratamento

15 Pode ser percebido em vários artigos como: Carrilho ameaçou publicar fotos de Bárbara nua na Net. noticioso dado à violência foi equânime.

Em geral, a imprensa preocupou-se tanto com o rompimento do relacionamento do casal quanto com o crime; porém, na maioria dos casos, as discussões foram relacionadas ao crime e seus desdobramentos (como pareceres e decisões judiciais). No caso brasileiro, houve uma discussão sobre a aplicabilidade ou não da Lei Maria da Penha, o que tende a aparentar uma maior consciência sobre este tipo de violência, mas estas discussões só surgiram na imprensa após terem aparecido nos tribunais. Portanto, não problematizaram a questão, apenas a descreveram.

Embora nenhuma peça analisada apresente, claramente, a dicotomia entre esfera pública e privada ou tente sequer desafiá-la, é importante ler as entrelinhas porque, como explica Mansbridge e Okin (2007: 337 apud Simões 2011: 270):

$$
\begin{aligned}
& \text { Desafiar a dicotomia } \\
& \text { público/privado significa insistir } \\
& \text { na não-trivialidade e na não- } \\
& \text { exclusão do debate público } \\
& \text { central das preocupações íntimas } \\
& \text { e domésticas. Significa insistir } \\
& \text { que o que se passa entre um }
\end{aligned}
$$


homem e uma mulher em sua casa, mesmo no seu quarto, é criado por e, simultaneamente, cria o que se passa nas legislaturas e nos campos de batalha. [...] A própria existência da vida privada, o reconhecimento da sua extensão e limites, e os tipos de comportamento aceitável dentro dela resultam de decisões formais e informais tomadas em público, nas legislaturas, nos tribunais, nas burocracias, na imprensa, nas ondas da rádio.

Não conseguimos perceber uma evolução cronológica da cobertura noticiosa portuguesa em face da brasileira, ainda que o caso português seja mais recente. Em ambos os casos, é possível perceber a existência de uma grande heterogeneidade. Alguns artigos detalharam as normas sobre o caso concreto e entraram em debates jurídicos, mas ainda sem transmitir a gravidade deste tipo de violência ao público. Um aspecto interessante a ser ressaltado é que os artigos de Portugal fizeram mais uso de fontes oficiais, como a polícia e o Ministério Público, para a coleta de suas informações. Esta percepção se coaduna com estudo de
Penedo (2003: 112) que, entretanto, apenas tratou de notícias de Portugal.

No estudo de caso sobre a
imprensa diária portuguesa foi
também possível constatar a
preponderância das fontes oficiais
na formatação das notícias. É
predominantemente através das
fontes oficiais, e da polícia em
particular, que os dados sobre
ocorrências criminais são
carreados para as notícias.

Em estudo sobre os meios de comunicação e o discurso prisional, Simões (2013: 50) percebe que o discurso dos jornais se apresenta "profundamente marcado por enquadramentos institucionalizados, que as fontes de informação transportam nos seus discursos e que são absorvidos, de forma acrítica e «natural», pelo discurso mediático". A autora salienta, assim, que a imprensa tende a "representar outros poderes, também eles disciplinadores e normalizadores, cuja visibilidade leva implícitos mecanismos de exclusão" (Simões, 2013: 50).

Nos dois casos, a violência contra as mulheres não foi tratada como uma violação dos direitos humanos, nem um desrespeito à dignidade. $\mathrm{O}$ fato 
de nenhum texto jornalístico mencionar a violência contra as mulheres como uma violação dos direitos humanos demonstra a superficialidade da cobertura midiática dos crimes, o que já se percebia do estudo de Penedo (2003: 111): “O conhecimento produzido a partir das notícias criminais é um conhecimento do senso comum que tende a simplificar a leitura da realidade e escapa à complexidade da abordagem científica [...]". Enquanto isso, novas leis importantes foram aprovadas e Tribunais Superiores se manifestaram em casos de violência doméstica de forma satisfatória.

A ausência da menção da violência contra as mulheres como uma violação dos direitos humanos demonstra ainda uma desconexão entre o positivado e o noticiado, bem como uma certa tendência amenizadora, quiçá normalizadora ou, nas palavras de Carter (2004: 13), a banalização do que é extraordinário. Simões (2011: 386) aponta que "no momento em que as agressões contra as mulheres perpetradas por um parceiro íntimo contornam a barreira que as separam da publicidade, estas não tendem a ser objecto de um profundo e aturado debate". O tratamento noticioso dessas notícias costuma ser descritivo e superficial, mantendo a ideia do "pessoal" e não do "político". No mesmo sentido de Carter, Simões (2011: 387) explica que “a desvalorização da violência contra as mulheres praticada no espaço privado e em contextos de intimidade" pode (e tem sido) interpretada como “instrumental para a normalização dos comportamentos extraordinários".

Em razão da visibilidade que os meios de comunicação possuem, é necessário refletir sobre os sentidos produzidos e as temáticas colocadas (e como o são) no discurso público. Grande parte da população não tem acesso a questões jurídicas e legislativas, nem mesmo compreendem o "juridiquês", servindo-se do que a mídia transmite para conhecer as normas e os avanços legislativos. Se a mídia omite algo ou não trata a temática com a problematização necessária, preferindo uma abordagem superficial, este é o enquadramento ao qual o público terá acesso. No caso da violência contra as mulheres, a não apresentação do crime como uma violação dos direitos humanos 
transparece a ideia de um crime comum, banalizado, contribuindo para o silêncio e a perpetuação da opressão de género.

É preciso repensar a maneira de apresentar os casos que envolvam crimes que outrora foram pensados como da ordem privada. É preciso conscientizar as/os jornalistas sobre o seu papel e a sua responsabilidade de conscientização da população sobre as temáticas que trata. Acreditamos que poderia ser oportuno que fosse ofertada e, posteriormente exigida, uma capacitação específica sobre leis, crimes e fatos históricos aos agentes que atuam nos contextos de produção para garantir uma cobertura noticiosa mais aprofundada e plena.

\section{Considerações finais}

Com os novos diplomas legislativos, inclusive a recente lei brasileira de 2015, que acrescenta o feminicídio ao Código Penal, a sociedade enfrenta os desafios de conhecer as normas e exigir a sua aplicação. Foi através de um processo de décadas que foram conquistadas mudanças legislativas inegáveis, algumas delas recentes, no combate à violência contra as mulheres, especificamente no que se refere ao âmbito doméstico. É necessário, pois, questionar se estão sendo corretamente aplicadas, se a população tem conhecimento pleno sobre elas, e se não é a certeza da impunidade que leva os agressores a continuar a exercer violência sobre suas parceiras.

Nos casos em tela, as vítimas realizaram uma denúncia contra o agressor, o que é essencial para coibir as práticas criminosas; porém, diante de inúmeros avanços legislativos vislumbrados nas últimas décadas, perceber que nenhum dos textos jornalísticos, de nenhum dos países analisados, menciona a violência contra as mulheres como uma violação dos direitos humanos, situação já positivada em normas internacionais, regionais e nacionais, parece-nos preocupante. A violência contra as mulheres não foi tratada como uma violação dos direitos humanos, nem mesmo um desrespeito à dignidade. Também não se percebe uma evolução/aprimoramento da cobertura noticiosa entre 2008 (Brasil) e 2013 (Portugal). Os textos predominantemente descrevem o 
ocorrido, mas não o problematizam (criticamente).

Apesar de a análise contemplar um número reduzido de peças, verificou-se que em alguns textos procuram-se motivos para os crimes, por vezes até com um tom justificativo. Para afirmar isto com mais propriedade, seria necessário aprofundar o estudo, coletar mais dados e alargar o corpus de análise. De qualquer forma, é preciso ter atenção às entrelinhas, pois a repetição (e partilha) de discursos pode caracterizar e perpetuar uma ideologia (hegemônica). Nas palavras de Bakhtine (apud Ponte, 2004: 17), "Esses discursos partilhados constituem a 'ideologia quotidiana', 'conjunto de reflexos e de refracções da realidade social e natural realizadas pelo cérebro humano, expressas e fixadas pela palavra”.

Para este estudo exploratório não foi levada em consideração a política editorial dos meios de comunicação social, nem as/os jornalistas que assinaram os textos, uma vez que nos centrámos na apresentação de um esboço geral das peças que chegam ao público leitor e que podem, por conseguinte, influenciar o modo como este interpreta e se posiciona em relação aos assuntos noticiados. Neste sentido, um caminho para futuras investigações será o de relacionar quem escreve o artigo à abordagem apresentada, verificar se possui conhecimentos específicos sobre a área e se só escreve sobre determinados assuntos, contrapor os textos jornalísticos à política editorial e às seções do tipo de mídia, bem como explorar os gêneros jornalísticos mais utilizados. Parece-nos ainda que a análise dos comentários, em contraponto à notícia em si, pode ser um terreno fértil para percebermos como as/os leitoras/es interpretam e promovem as mensagens veiculadas acerca da violência contra as mulheres.

Deste modo, consideramos que os meios de comunicação social devem perceber a influência que exercem nos públicos para que se qualifiquem e apresentem os textos jornalísticos com abordagens que, apesar de compreensíveis, sejam mais técnicas e profundas. É preciso tratar a violência contra as mulheres como um crime que, por razões históricas e culturais, caracteriza-se como um problema social, para que não seja banalizada ou 
tratada como uma situação isolada, pontual, desprovida de um caráter ideológico. É necessário tratar a violência contra as mulheres com a gravidade merecida (e positivada nas normas).

\section{Referências bibliográficas}

Carter, Cynthia (2004), “Quando o «extraordinário» se torna «banal $\gg$. As Notícias quotidianas de Violência Sexual", in Maria João Silveirinha (org.), Portugal. As Mulheres e os Media. Lisboa: Livros Horizonte, 1328.

Cavalcanti, Stela Valéria Soares Farias (2005), “A violência doméstica como violação dos direitos humanos", Revista Jus Navigandi, 10, 901. 5 p. Consultado a 11.03.2015, em http://jus.com.br/artigos/7753.

Cintra, Antonio Carlos Araujo; Dinamarco, Cândido Rangel \& Grinover, Ada Pellegrini (2009), Teoria Geral do Processo. São Paulo: Malheiros.

Declaração sobre a Eliminação da Violência contra a Mulher (1993).
Consultado a 03.03.2015, em http://direitoshumanos.gddc.pt/3_4/IIIP AG3 4_7.htm.

Declaração Universal dos Direitos Humanos (1948). Consultado a 03.03.2015, em http://www.dhnet.org.br/direitos/deconu /textos/integra.htm.

Dias, Maria Berenice (2008), A Lei Maria da Penha na Justiça: a efetividade da Lei 11.340/2006 de combate à violência doméstica e familiar contra a mulher. São Paulo: Editora Revista dos Tribunais.

Duarte, Madalena (2013), "O lugar do Direito na violência contra as mulheres na relação de intimidade", Revista Gênero \& Direito. 21 p. Consultado a 18.03.2015, em http://periodicos.ufpb.br/ojs/index.php/g ed/article/download/16946/9646.

Fidalgo, Fernando; Mill, Daniel (2007), "A Internet como suporte técnico para coleta de dados para pesquisas científicas". 19 p. Consultado a 20.10.2015, em http://intranet.ufsj.edu.br/rep_sysweb/Fi le/vertentes/Vertentes_29/mill_e_fidalg o.pdf. 
FRA (2014), Relatório "Violência contra as mulheres: um inquérito à escala da União Europeia - Síntese dos resultados". Consultado a 25.03.2015, em http://www.cig.gov.pt/wpcontent/uploads/2014/11/Viol\%C3\%A

Ancia-contra-as-mulheres-uminqu\%C3\% A9rito-\%C3\% A0-escala-daUE.pdf.

Gallagher, Margaret (2004), “O Imperialismo de batom e a nova ordem mundial: As Mulheres e os Media no final do século XX", in Maria João Silveirinha (org.), Portugal. As Mulheres e os Media. Lisboa: Livros Horizonte, 69-96.

Gil, Antônio Carlos (2014), Métodos e técnicas de pesquisa social. São Paulo: Atlas.

Lei n. 11.340 (2006), de 7 de agosto. Consultado a 04.03.2015, em http://www.planalto.gov.br/ccivil_03/_a to2004-2006/2006/lei/111340.htm.

Machado, Helena (2004), "Cidadania polifónica e a (in)justiça para as mulheres", Revista da Associação
Portuguesa de Estudos sobre as Mulheres, 13-26.

Machado, Helena; Santos, Filipe (2010), “O desaparecimento de Madeleine McCann: Drama público e julgamento mediático na imprensa portuguesa", Justiça, ambientes mediáticos e ordem social, 57-83.

Maxwell, Kimberly; Huxford, John; Borum, Catherine; Hornik, Robert (2000), "Covering Domestic Violence: How the O.J. Simpson Case Shaped Reporting Of Domestic Violence in the News Media", Journalism and Mass Communication Quarterly, 77, n. 2, 258-272.

Miranda, Cynthia Mara (2012), "Brasil, Canadá e a Integração de Políticas de Gênero a partir da Plataforma de Ação de Pequim", Interfaces Brasil/Canadá, 12(15), 83-100.

OMA (2015), Relatório Anual de 2015. Consultado a 06.05.2016, em http://www.umarfeminismos.org/image s/stories/oma/2015/OMA_2015_Relat\% C3\%B3rio_Anual_Final.pdf. 
Organização Mundial de Saúde - OMS (2013), "16 Days of Activism Against

Gender Violence". Consultado a 25.03.2015, em http://www.who.int/violence_injury__ prevention/violence/global_campaign/1 $\underline{6 \text { days/en/. }}$

Penedo, Cristina Carmona (2003), O Crime nos Media. Lisboa: Livros Horizonte.

Pinafi, Tânia (2007), "Violência contra a mulher: políticas públicas e medidas protetivas na contemporaneidade". $7 \mathrm{p}$. Consultado a 28.03.2015, em http://www.historica.arquivoestado.sp.g ov.br/materias/anteriores/edicao21/mate ria03/.

Ponte, Cristina (2004), Leitura das Notícias. Lisboa: Livros Horizonte.

Rajs, María Soledad Rojas (2014), "La violencia contra las mujeres en las noticias en México: el tratamiento acrítico y dispar de un grave problema social”, Acta Sociológica, 65, 37-64.

Ross, Karen (2007), "The Journalist, the housewife, the citizen and the press: Women and men as sources in local news narratives", Journalism, 8(4): 449473.

Silveirinha, Maria João (2004), “Os Media e as Mulheres: Horizontes de Representação, de Construção e de Práticas Significantes", in Maria João Silveirinha (org.), Portugal. As Mulheres e os Media. Lisboa: Livros Horizonte, 5-12.

Simões, Rita Joana Basílio (2011), "Crime, Castigo e Género nas Sociedades Mediatizadas: Políticas de (In)justiça dos Discursos dos Media". Dissertação de Doutoramento em Letras, Universidade de Coimbra.

Simões, Rita Joana Basílio (2013), "Disciplina e Normalização: O Discurso Prisional no Espaço Público Mediatizado", in Rita Basílio Simões; Carlos Camponez \& Ana Teresa Peixinho (orgs.), Portugal. Justiça e Comunicação: O Diálogo (Im)possível. Coimbra: Imprensa da Universidade de Coimbra, 33-51.

Simões, Rita Joana Basílio (2014), “Do «pessoal ao político»: tensões, paradoxos e implicações da 


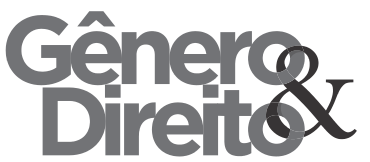

Periódico do Núcleo de Estudos e Pesquisas sobre Gênero e Direito

Centro de Ciências Jurídicas - Universidade Federal da Paraíba

V. 6 - No 01 - Ano 2017 - Mídia, Gênero \& Direitos Humanos ISSN | 2179-7137 | http://periodicos.ufpb.br/ojs2/index.php/ged/index

mediatização da violência contra as mulheres em Portugal", Media \& Jornalismo, 25, 14(2), 33-51.

SPM (2012), "Nos 16 dias do ativismo, SPM intensifica enfrentamento à violência contra a mulher”. Consultado a 20.03.2015, em

http://www.spm.gov.br/noticias/ultimas noticias/2012/11/27-11-nos-16-diasdo-ativismo-spm-intensificaenfrentamento-a-violencia-contra-amulher.

UNWomen (2016), "Facts and Figures: Ending Violence Against Women". Consultado a 08.05.2016, em http://www.unwomen.org/en/what-wedo/ending-violence-againstwomen/facts-and-figures.

Weldon, Laurel; Htun, Mala (2013), "Feminist mobilization and progressive policy chance: why governments take action to combat violence against women", Gender \& Development, 21(2), 231-247.

Zoonen, Liesbet van (2004), "O Movimento das Mulheres e os Media: A Construção de uma Identidade Pública”, in Maria João Silveirinha (org.), Portugal. As Mulheres e os Media. Lisboa: Livros Horizonte, 155-174.

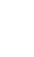

